\title{
Dimensions and volumes of left atrium and ventricle determined by single beam echocardiography
}

\author{
F. J. ten Cate, F. E. Kloster, W. G. van Dorp, G. T. Meester, and J. Roelandt \\ From the Department of Clinical Echocardiography, Thoraxcenter, Erasmus University, Rotterdam, the \\ Netherlands
}

This study further extends the clinical usefulness of the estimation of cardiac chamber size by means of single echocardiographic dimensions. In 24 patients left atrial size was calculated from an anteroposterior standard echographic dimension and correlates $(r=0.88)$ with the left atrial surface area measured from selective cineangiograms in the right anterior oblique position. For clinical use a left atrial aortic dimensional ratio was derived as a valid index for the separation of normal and enlarged atrial cavities. An excellent correlation between angiographic and echographic derived volumes was found for left ventricular volumes from single left ventricular echographic dimensions in the 35 patients studied. Correlation coefficients for end-systolic and end-diastolic volumes were $r=0.96$ and $r=0.97$, respectively. As might be expected, calculated stroke volumes and ejection fractions from echocardiograms and angiograms correlated less well $(r=0.82$ and $r=0.79$, respectively). From these results and from studies published by others, despite theoretical limitations and several assumptions in the use of single left ventricular dimensions, it is concluded that calculations can be used with confidence for volume determinations in the majority of patients, including those with coronary artery disease and over a wide range of left ventricular dimensions and sizes. It appears that, provided these observations are extended, derived variables such as stroke volume and ejection fractions, can be obtained for the assessment of left ventricular function by non-invasive means.

The use of reflected ultrasound from external transducers to determine cardiac chamber size is a relatively recent development. The assessment of left atrial size was first attempted by Hirata et al. (1969). He found a good correlation between a single left atrial echo dimension and its area measured from cineangiograms in the right anterior oblique position. Left ventricular end-systolic and enddiastolic volumes estimated from single left ventricular echo dimensions and measured from left ventricular angiograms have been compared in many studies. The good agreement between both methods that has been demonstrated by many authors (Popp et al., 1969; Pombo, Troy, and Russell, I971a; Murray, Johnston, and Reid, 1972; Feigenbaum and Chang, 1972; Fortuin et al., 1971; Gibson, 1973; Ratshin et al., 1973) is surprising when one considers the geometry and the mathematics that are involved. Results obtained by other methods such as the Fick technique (Feigenbaum, Zaky, and Nasser, 1967; Popp and Harrison, 1970, 1970) and the indicator dilution technique (Pombo

Received 21 February 1974. et al., 197Ib) have also been used as a reference and again good correlations have been found. More recent echographic studies employ standardized techniques to obtain echoes both from the left side of the septum and from the endocardium of the left ventricular posterior wall. This standardization refers to the patient position, transducer position, control of gain settings, and the use of stripchart recorders (Feigenbaum and Chang, 1972; Popp and Harrison, 1973), and has added validity to many dimensional measurements. The purpose of the present study is to investigate further the role of echocardiography in the derivation of left atrial and ventricular size by comparing the results with those obtained with quantitative angiocardiography in a variety of clinical conditions.

\section{Subjects}

\section{Left atrial dimensional study}

Studies were made on 24 patients, 12 male and 12 female, aged 12 to 65 years. The patients (Table $\mathrm{I}$ ) included 6 with coronary artery disease, 12 with valvular heart disease, 3 with asymmetrical septal 
TABL E I Results of left atrial dimension studies

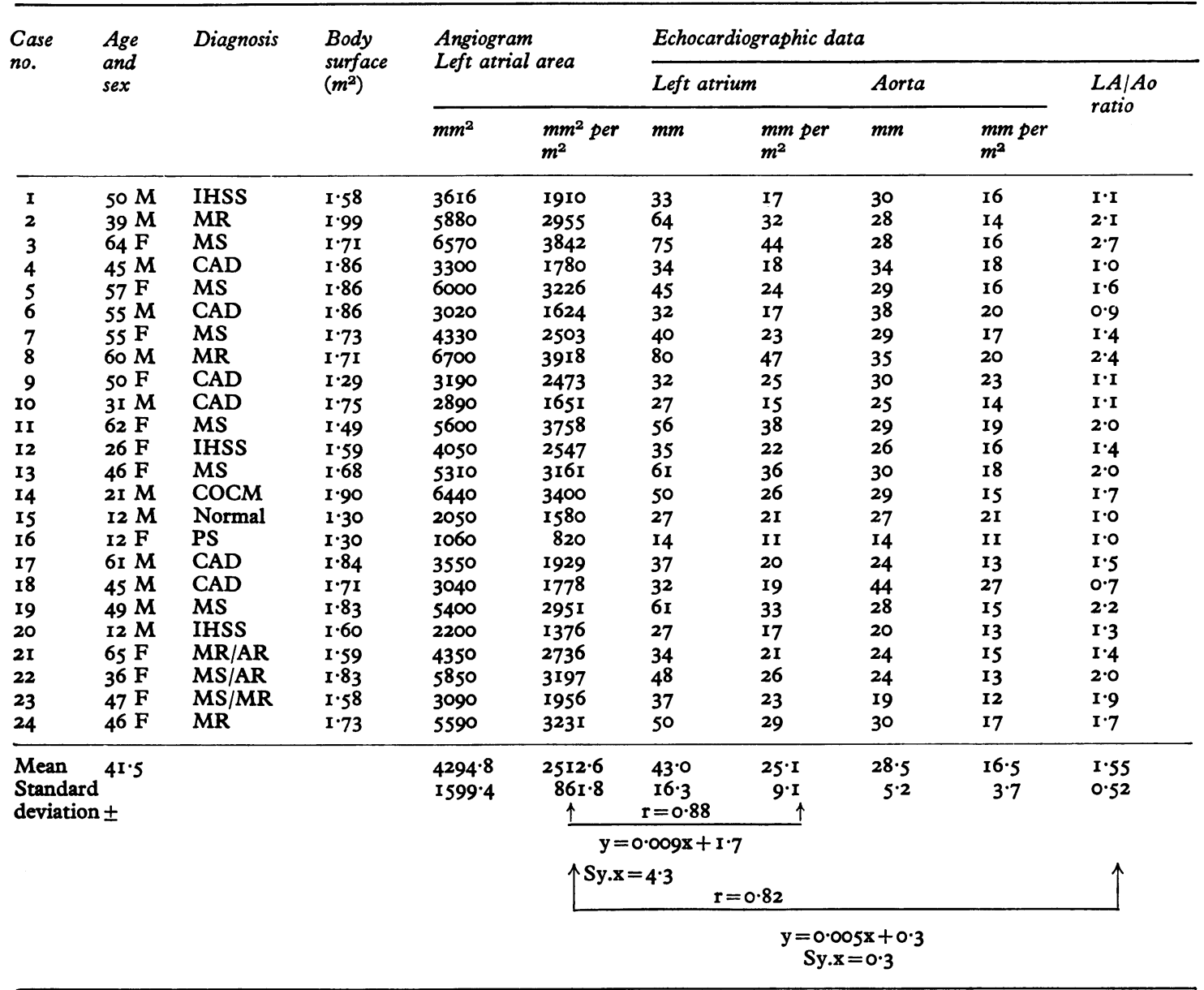

Abbreviations: Ao, aorta; AR, aortic regurgitation; CAD, coronary artery disease, COCM : congestive cardiomyopathy, IHSS: idiopathic hypertrophic subaortic stenosis, LA: left atrium, MR: mitral regurgitation, MS: mitral stenosis, PS: pulmonary stenosis.

hypertrophy, one with cardiomyopathy, one with pulmonary stenosis and one with no demonstrable heart disease (functional murmur). All underwent routine diagnostic cardiac catheterization and quantitative angiocardiography. The echocardiographic examination was performed within 24 hours before or after the catheterization procedure and patient selection was only on the basis of the quality of the left atrial cineangiograms. Left atrial and aortic root dimensions were also measured in 25 normal subjects. The absence of heart disease was based on their history, the normal clinical cardiac examination, electrocardiogram, and chest $x$-ray. The same measurements were also made in the last 27 patients presenting at the outpatient clinic with mitral stenosis. All had the typical auscultatory findings of mitral stenosis, further confirmed by other non-invasive methods; of these the abnormal mitral valve motion pattern on the echocardiogram was the most consistent one.

\section{Left ventricular dimensional study}

Of 50 consecutive patients undergoing diagnostic heart catheterization, 42 had suitable echocardiograms ( $84 \%$ ). In 35 both the echocardiograms and angiocardiograms permitted left ventricular volume calculations (70\%). These 35 patients, 32 male and 3 female, aged 16 to 64 years presented with a wide spectrum of cardiac diseases (Table 2). They include 19 with coronary artery disease; I4 with valvular disease; one with asymmetrical septal hypertrophy, and one with Ebstein's disease. Their echocardiographic study was performed within a 24hour period before or after the catheterization procedure. 
TABLE 2 Results of left ventricular volume studies

\begin{tabular}{|c|c|c|c|c|c|c|c|c|c|c|c|c|c|c|c|}
\hline \multirow[t]{2}{*}{$\begin{array}{l}\text { Case } \\
\text { no. }\end{array}$} & \multirow[t]{2}{*}{$\begin{array}{l}\text { Age } \\
\text { and } \\
\text { sex }\end{array}$} & \multirow[t]{2}{*}{ Diagnosis } & \multirow[t]{2}{*}{$\begin{array}{l}\text { Body } \\
\text { surface } \\
\text { area } \\
\left(m^{2}\right)\end{array}$} & \multirow[t]{2}{*}{$\begin{array}{l}\text { Sys- } \\
\text { tolic } \\
\text { dia- } \\
\text { meter } \\
(\mathrm{mm})\end{array}$} & \multirow[t]{2}{*}{$\begin{array}{l}\text { Dia- } \\
\text { stolic } \\
\text { dia- } \\
\text { meter } \\
(\mathrm{mm})\end{array}$} & \multicolumn{2}{|c|}{$\begin{array}{l}\text { End- } \\
\text { diastolic } \\
\text { volume } \\
\left(\mathrm{ml} / \mathrm{m}^{2}\right)\end{array}$} & \multicolumn{2}{|c|}{$\begin{array}{l}\text { End- } \\
\text { systolic } \\
\text { volume } \\
\left(\mathrm{ml} / \mathrm{m}^{2}\right)\end{array}$} & \multicolumn{2}{|c|}{$\begin{array}{l}\text { Stroke } \\
\text { volume } \\
\text { volume } \\
\left(\mathrm{ml} / \mathrm{m}^{2}\right)\end{array}$} & \multicolumn{2}{|c|}{$\begin{array}{l}\text { Ejection } \\
\text { fraction } \\
(\%)\end{array}$} & \multicolumn{2}{|c|}{ Heart rate } \\
\hline & & & & & & Echo & Angio & Echo & Angio & Echo & Angio & Echo & Angio & Echo & Angio \\
\hline I & 2I M & Ebstein & $I \cdot 6$ & 37 & 53 & 94 & 97 & 32 & 34 & 64 & 63 & 66 & 67 & 80 & 108 \\
\hline 2 & $31 \mathrm{M}$ & CAD & $1 \cdot 75$ & 40 & 54 & 94 & 91 & 38 & 37 & 56 & 54 & 60 & 59 & 75 & 62 \\
\hline 3 & $43 \mathrm{M}$ & AS/AR & $I \cdot 72$ & 43 & 54 & 97 & 103 & 49 & 58 & 48 & 45 & 50 & 44 & 90 & 122 \\
\hline 4 & $37 \mathrm{M}$ & CAD & $1 \cdot 75$ & 44 & 56 & 104 & 97 & 50 & 40 & 54 & 57 & 52 & 59 & 60 & 66 \\
\hline 5 & $55 \mathrm{M}$ & CAD & $I \cdot 9$ & 40 & 52 & 75 & 82 & 36 & 38 & 39 & 44 & $5 I$ & 54 & 60 & 66 \\
\hline 6 & $40 M$ & CAD & $I \cdot 9$ & 37 & 50 & 76 & 83 & 23 & 29 & 53 & 54 & 70 & 65 & 70 & 80 \\
\hline 7 & $42 M$ & MS/MR/AS/AR & $I \cdot 64$ & 50 & 56 & I13 & 100 & 79 & 57 & 34 & 43 & 29 & 33 & 70 & 97 \\
\hline 8 & $46 \mathrm{M}$ & CAD & $I \cdot 73$ & 40 & 53 & 89 & 112 & 38 & 45 & $5 \mathrm{I}$ & 67 & 57 & 60 & 60 & 73 \\
\hline 9 & $5 \mathrm{IF}$ & CAD & $1 \cdot 47$ & 36 & 46 & 70 & 77 & 32 & $4 \mathrm{I}$ & 38 & 36 & 56 & 47 & 60 & 75 \\
\hline ro & 6I $M$ & MS/MR & $1 \cdot 84$ & 30 & 43 & 45 & 49 & 16 & I6 & 29 & 33 & 65 & 66 & 60 & 57 \\
\hline II & $50 \mathrm{~F}$ & MS & $1 \cdot 54$ & 43 & 50 & 84 & 87 & 55 & 48 & 29 & 39 & 36 & 45 & 65 & 84 \\
\hline 12 & 6r M & CAD & $1 \cdot 84$ & 57 & 64 & 150 & 162 & 107 & 97 & 43 & 65 & 27 & 40 & 65 & 54 \\
\hline 13 & $43 M$ & CAD & $I \cdot 74$ & 45 & 49 & 72 & 89 & 50 & 46 & 22 & 43 & $3 I$ & 48 & 80 & 121 \\
\hline 14 & $46 M$ & CAD & $1 \cdot 9$ & 37 & 53 & 79 & 86 & 27 & 34 & 52 & 52 & 66 & 6I & 70 & 64 \\
\hline I5 & $52 M$ & CAD & I.97 & 43 & 53 & 77 & 97 & 43 & 37 & 34 & 60 & 45 & 62 & 70 & 64 \\
\hline 16 & $42 M$ & AR & 1.83 & 63 & 79 & 288 & 280 & 150 & 187 & 138 & 93 & 46 & 33 & 80 & 107 \\
\hline 17 & $46 M$ & CAD & $1 \cdot 92$ & 34 & 51 & 72 & 65 & 21 & 24 & 51 & 41 & 71 & 63 & 80 & 89 \\
\hline 18 & $64 \mathrm{~F}$ & MS & $x \cdot 70$ & 37 & 55 & 100 & 84 & $3 I$ & 29 & 69 & 55 & 70 & 65 & 90 & 123 \\
\hline I9 & $43 M$ & CAD & I.89 & $4 I$ & 53 & 80 & 79 & 39 & 40 & $4 \mathrm{I}$ & 39 & 51 & 49 & 80 & 82 \\
\hline 20 & $51 \mathrm{~F}$ & MS/MR & $r \cdot 69$ & 40 & 48 & 67 & 67 & 39 & 38 & 28 & 29 & 42 & 44 & 70 & 76 \\
\hline $2 I$ & $62 \mathrm{~F}$ & MS/MR & $1 \cdot 49$ & 46 & 56 & 122 & 117 & 67 & 68 & 55 & 49 & 45 & 42 & 70 & 80 \\
\hline 22 & $50 \mathrm{M}$ & AR & $1 \cdot 82$ & 37 & 58 & 109 & 107 & 28 & 33 & 81 & 74 & 74 & 69 & 70 & 70 \\
\hline 23 & $49 M$ & MS & $r \cdot 83$ & 45 & 56 & 99 & 108 & 52 & 52 & 47 & 56 & 48 & 52 & 70 & 82 \\
\hline 24 & $50 \mathrm{M}$ & CAD & $2 \cdot 02$ & 43 & 58 & 99 & IOI & 42 & 45 & 57 & 56 & 57 & 56 & 60 & 58 \\
\hline 25 & I2 $\mathrm{M}$ & IHSS & $1 \cdot 60$ & 32 & 44 & 57 & 66 & $2 I$ & 20 & 36 & 46 & 64 & 70 & 70 & 80 \\
\hline 26 & $42 M$ & CAD & $x \cdot 7$ & 31 & 42 & 45 & 55 & 18 & 15 & 27 & 40 & 59 & 72 & 70 & 85 \\
\hline 27 & $29 M$ & TR & $I \cdot 9$ & 29 & 43 & 44 & 46 & 13 & 15 & $3 \mathbf{I}$ & 3I & 71 & 68 & 70 & 77 \\
\hline 28 & $52 \mathrm{M}$ & CAD & $1 \cdot 78$ & 39 & 51 & 77 & 71 & 34 & 22 & 43 & 49 & 57 & 69 & 70 & 78 \\
\hline 29 & $47 \mathrm{M}$ & MR/TR & $1 \cdot 84$ & 45 & 59 & 117 & 115 & $5 I$ & 46 & 66 & 69 & 57 & 60 & 70 & 83 \\
\hline 30 & $38 \mathrm{M}$ & CAD & $2 \cdot 0^{\circ}$ & 40 & 58 & 99 & 107 & 34 & 48 & 65 & 59 & 67 & 56 & 60 & 65 \\
\hline $3 I$ & $45 \mathrm{M}$ & $\mathrm{CAD}$ & $I \cdot 71$ & 33 & 45 & 56 & 64 & 21 & 20 & 35 & 44 & 62 & 68 & 70 & 80 \\
\hline 32 & $16 \mathrm{M}$ & AS/VSD & $I \cdot 75$ & 37 & $5 I$ & 79 & IOI & $3 I$ & 37 & 48 & 64 & 62 & 63 & 70 & 79 \\
\hline 33 & $40 \mathrm{M}$ & CAD & 1.8 & 40 & 55 & 96 & 86 & 39 & 34 & 58 & 52 & 60 & 60 & 70 & 72 \\
\hline 34 & $49 \mathrm{~F}$ & MR & $1 \cdot 69$ & 55 & 62 & 150 & 183 & 100 & 134 & 50 & 49 & 33 & 27 & 70 & 80 \\
\hline \multirow[t]{4}{*}{35} & $44 M$ & CAD & 1.83 & 40 & 50 & 69 & 82 & 34 & 32 & 35 & 50 & 48 & 61 & 70 & 97 \\
\hline & & & Mean & $5 I \cdot 6$ & $40 \cdot 8$ & $92 \cdot 6$ & 97.0 & $44 \cdot 3$ & $45 \cdot 6$ & $48 \cdot 5$ & $51 \cdot 4$ & $54 \cdot 3$ & 55.9 & 70 & 76 \\
\hline & & & $\begin{array}{l}\text { andard } \\
\text { viation } \pm\end{array}$ & II·04 & $7 \cdot 29$ & $42 \cdot 3$ & $4 I \cdot 9$ & $29 \cdot 0$ & 33.5 & 19.5 & 13.2 & 13.08 & II $\cdot 7$ & 7 & 24 \\
\hline & & & & & & \multicolumn{2}{|c|}{$\begin{array}{l}r=0.97 \\
y=0.98 x \\
-2.22 \\
\text { Sy.x }=10.6\end{array}$} & \multicolumn{2}{|c|}{$\begin{array}{l}0.96 \\
y=0.83 x \\
+6.30 \\
\text { Sy.x }=8.3\end{array}$} & \multicolumn{2}{|c|}{$\begin{array}{l}0.82 \\
y=1 \cdot 21 x \\
\quad-14 \cdot 02 \\
\text { Sy.x }=11 \cdot 07\end{array}$} & \multicolumn{2}{|c|}{$\begin{array}{l}0.79 \\
y=0.88 x \\
\quad+4.94 \\
\text { Sy.x }=7.98\end{array}$} & & \\
\hline
\end{tabular}

AS, aortic stenosis; VSD, ventricular septal defect; TR, tricuspid regurgitation.

For other abbreviations, see footnote to Table I.

\section{Methods}

\section{Echocardiographic studies}

Echocardiographic studies were done with the ECHOcardioVISOR, an instrument that has both the conventional single element and the multiscan facility (Bom et al., 1973; Roelandt et al., 1973). All studies were performed using a $1.9 \mathrm{~cm}$ diameter, $2.25 \mathrm{mHz}$, and $7.5 \mathrm{~cm}$ focused transducer. The transducer is pulsed for I msec and receives during a period of $200 \mu \mathrm{sec}$. The repetition rate is 1024 impulses per second. The echo signals were recorded in the $M$-mode using a Honeywell Linescanrecorder (Visicorder 1856) on Kodak light sensitive paper (Linagraph type 1895).

Patients were examined in the supine position. Turning the patient slightly on his left side sometimes allows better visualization of the interventricular septum and left ventricular posterior wall simultaneously. The standard position of the transducer is in that intercostal space where the characteristic rapid anterior mitral leaflet motion is recorded while the transducer is held perpendicularly on the chest and as close as possible 


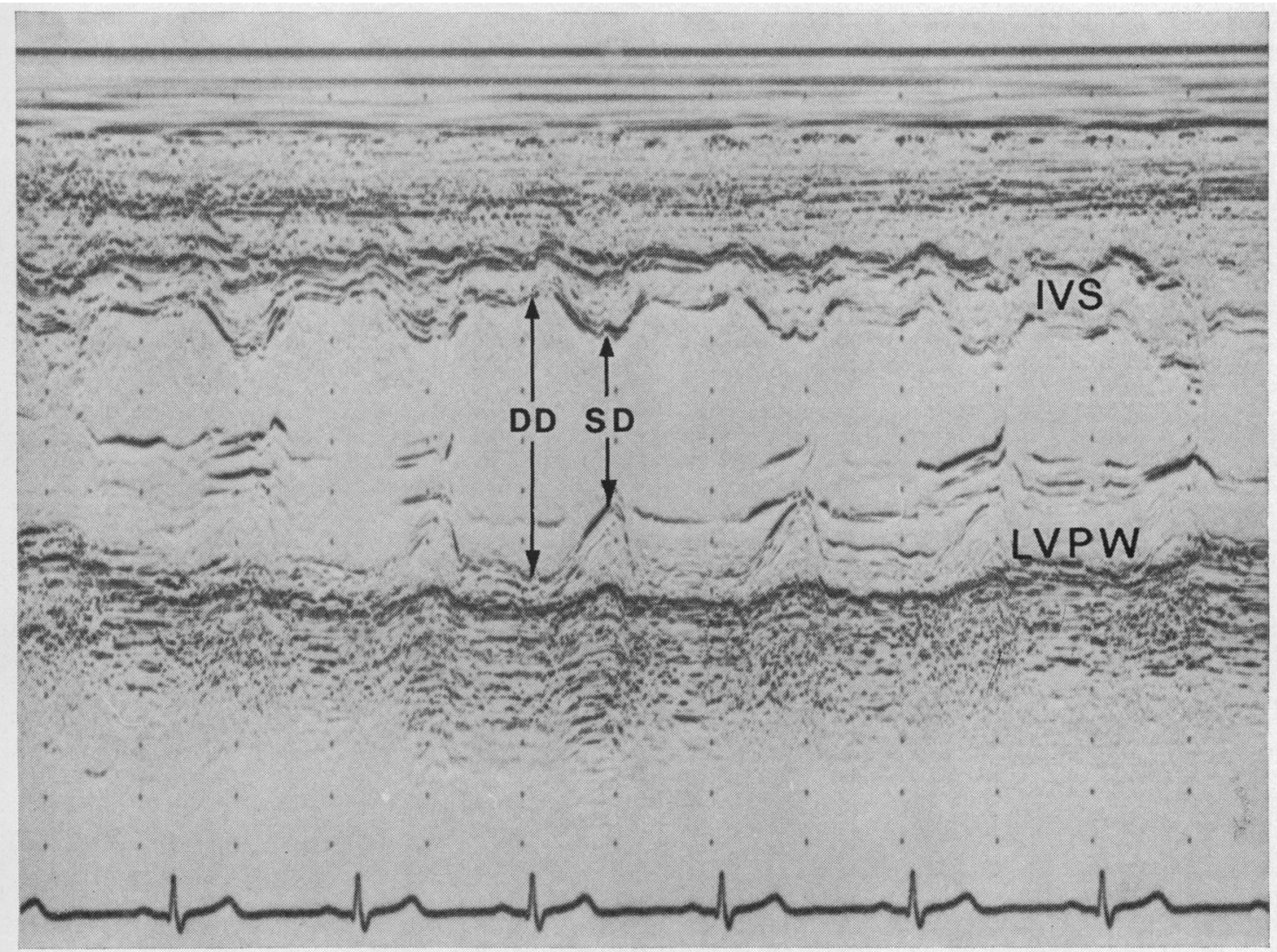

FIG. I Transverse scan perpendicular to the long axis of the left ventricle. The left ventricular end-diastolic $(D D)$ and end-systolic dimensions $(S D)$ are measured where the left ventricular cavity is largest and at their respective times in the cycle as indicated by the electrocardiogram. Calibration points are $I \mathrm{~cm}$ apart. (Abbreviations: IVS =interventricular septum; $L V P W=$ left ventricular posterior wall.)

to the left sternal border. The long-axis plane of the heart is then defined by reorienting the transducer from this position slightly to the aortic root (medial-superior direction) and to the apex of the heart (lateral-inferior direction). A continuous sectorscan through this plane is then performed and recorded (Feigenbaum and Chang, 1972; Popp and Harrison, 1973). Subsequently, selective recordings of the aorta and left atrium are made. The transducer is then aimed at a point just below the tip of the mitral valve leaflets. From this position, the transducer is angled so as to be perpendicular to the plane of the long axis. This is referred to as the transverse, or T-scan (Henry, Clark, and Epstein, 1973). Several Tscans are performed and the largest left ventricular diameter defined (Fig. I). Recordings of the left ventricular dimensions are then made during several cardiac cycles, with the transducer in this position. Different time-sensitive gain settings are used to obtain the highest quality echocardiograms. Representative timemotion recordings are shown in Fig. 2. Panel A shows echocardiographic traces from the anterior and posterior aortic root and left atrial dimensions. An example of left ventricular echocardiogram, where both the endocardium of the left side of the interventricular septum and of the left ventricular posterior wall are seen is shown in panel $B$.

\section{Angiocardiographic studies}

Selective single plane left atrial cinenagiograms were made at 80 frames per second in the right anterior oblique position. Urogafin 60 per cent $(0.75 \mathrm{ml} / \mathrm{kg}$ body weight) was injected either in the left atrium or in the pulmonary artery. Quantitative single plane left ventricular cineangiograms were all done in the right anterior oblique position at 80 frames per second. The same amount of Urografin was injected into the left ventricle through a retrograde catheter properly positioned in the left ventricle. An electrocardiographic lead, cineframe markers, and the timing of the contrast injection were recorded on a multichannel recorder. 


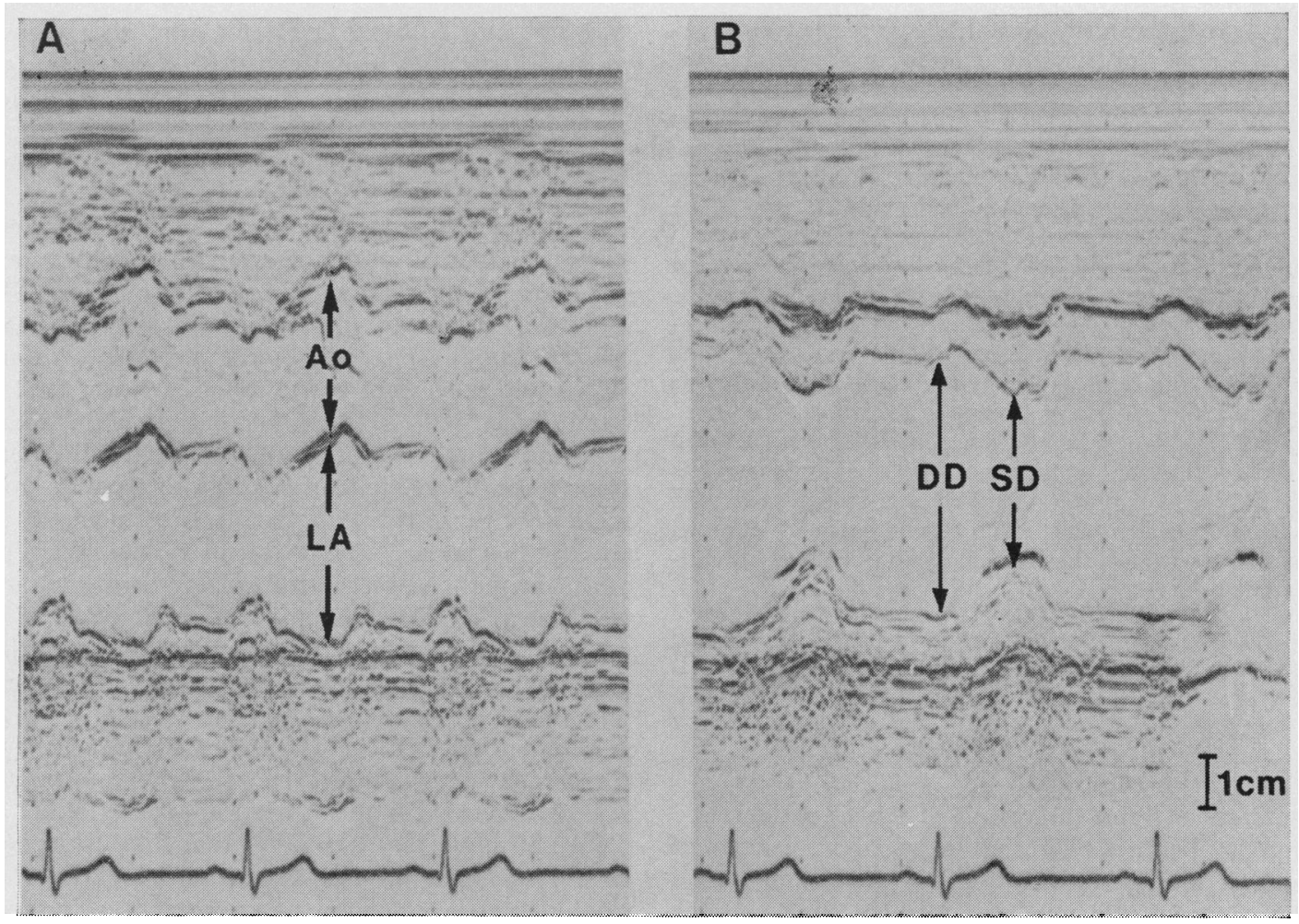

FIG. 2 Panel $A$ shows a standard echocardiogram used for left atrial dimensional measurements. The aortic walls and the left atrial posterior wall are visualized. Arrows indicate the internal dimensions of both the aortic root $(A o)$ and left atrium $(L A)$. Calibration points are $I \mathrm{~cm}$ apart. $A$ standard left ventricular echocardiogram is represented in panel $B$. Left ventricular dimensions at end-diastole $(D D)$ and at end-systole $(S D)$ are indicated by arrows. The diastolic dimension $(D D)$ is measured at the $R$ peak of the simultaneously recorded electrocardiogram.

\section{Echocardiographic and angiocardiographic data analysis}

Echo data Only the best quality tracings of each patient were selected for this study. For left atrial dimensional measurements, echocardiographic recordings were used where the anterior and posterior aortic wall and left atrial posterior wall were seen during several cardiac cycles. The typical motion patterns of these structures have been described elsewhere (Hirata $e t$ al., 1969; Feigenbaum and Chang, 1972; Popp and Harrison, 1973). Arbitrarily the distance between the anterior surfaces of the anterior and posterior aortic walls was considered to be the dimension of the aortic root, and the distance between the posterior aortic wall and the anterior echoes of the left atrial posterior wall was taken as the left atrial standard anteroposterior dimension (Popp and Harrison, 1973). All measurements were done at end-systole at which time the largest left atrial diameter was considered to be present. Measurements during 3 to 5 consecutive cardiac cycles were made and expressed in mm (see Fig. 2A). For analysis of the left ventricular dimensions, tracings were selected where the endocardium of both the interventricular septum and left ventricular posterior wall were clearly seen simultaneously (Fig. 2B). Measurements were done at the peak of the $R$ wave for the end-diastolic dimensions, while the smallest distance between the interventricular septum and left ventricular posterior wall was considered as the end-systolic dimension. End-systolic volumes were calculated as $\mathrm{r} \cdot 047 \mathrm{SD}^{3}$ (where SD is the endsystolic dimension in $\mathrm{cm}$ ) and end-diastolic volume as $\mathrm{I} \cdot 047 \mathrm{DD}^{3}$ (where $\mathrm{DD}$ is the end-diastolic dimension in $\mathrm{cm}$ ). Indeed, the volume of a prolate ellipse is $(\pi / 6)$ $\mathrm{LD}^{2}$, where $\mathrm{L}$ is the long and $\mathrm{D}$ the minor axis. If one assumes $\mathrm{L}=2 \mathrm{D}$, the formula becomes $(2 \pi / 6) \mathrm{D}^{3}$ or $\mathrm{I} \cdot 047 \mathrm{D}^{3}$. Stroke volumes were calculated as the difference between end-diastolic and end-systolic volumes. Ejection fraction is stroke volume divided by enddiastolic volume. All the volumes were corrected for body surface area and expressed in $\mathrm{ml} / \mathrm{m}^{2}$. 
Angiocardiographic data The left atrial area visualized on the right anterior oblique cineangiograms was measured by planimetry using a special projecting table (Autotrol Corp-model 3400 Curve Tracer). The largest left atrial area-curve was used for comparison with the left atrial echo dimension. The areas were corrected for $x$-ray magnification using a filmed standard grid at the mid-level of the heart. The left atrial area is expressed in $\mathrm{mm}^{2}$. Left ventricular volumes were calculated from the area and length of the left ventricle measured on the same projecting table and corrected for $x$-ray magnification by means of the area-length method for volume calculation for films taken in the right antero-oblique position as described by Greene et al. (1967). The cineframe at the R-peak of the electrocardiogram was taken as the end-diastolic volume and the smallest volume as the end-systolic volume. Stroke volume of the left ventricle is end-diastolic minus end-systolic volume. Ejection fraction is the ratio of systolic volume to enddiastolic volume.

Statistical analysis Data were analysed by a statistical programme on a PDP 9 computer, using standard regression techniques (Fisher, 1970).

\section{Results}

\section{Left atrial size studies}

The diagnosis and the results of the 24 patients are given in Table $\mathrm{I}$. The left atrial areas calculated from angiographic and the left atrial and aortic echographic dimensions are listed with and without adjustment for body surface area. The mean angiographic left atrial area was $4294 \mathrm{~mm}^{2}\left(2512.6 \mathrm{~mm}^{2}\right.$ / $\mathrm{m}^{2}$ body surface area), with a standard deviation (SD) of $1599 \mathrm{~mm}^{2}\left(86 \mathrm{I} \mathrm{mm} / \mathrm{m}^{2}\right.$ body surface area). The mean left atrial echocardiographic dimension was $43.0 \mathrm{~mm}$ with a SD of $16.3 \mathrm{~mm}$, after adjustment for variation in body surface area it was 25 . I $\mathrm{mm}$ with a SD of 9.I mm. Fig. 3A shows the relation between the body surface area adjusted angiographic left atrial areas and left atrial echographic dimensions. The correlation coefficient $\mathrm{r}$ is 0.88 . The calculated regression equation was left atrial dimension $=0.009 \mathrm{x}$ (angiographic) $+\mathrm{I} \cdot 7$ with a standard error of the estimate (Sy.x) of $4.3 \mathrm{~mm} / \mathrm{m}^{2}$. The left atrial dimensions of patients with valvular heart disease and the one with cardiomyopathy (mean: $54.3 \mathrm{~mm} \pm 14.8$ ) were clearly different from the left atrial dimensions in the other II patients (mean $30.0 \mathrm{~mm} \pm 6 \cdot 2)$. The range of the left atrial dimensions is large, and it is impossible to separate normals from those with left atrial enlargement. In an attempt to standardize and to improve the reliability of the estimation of left atrial enlargement, the ratio of left atrial to aortic dimension was calculated in all patients. Fig. ${ }_{3} B$ shows the correlation between this ratio and the left atrial area $(r=0.82)$. This ratio was found to be higher than $\mathrm{r} \cdot 0$ in only 2 of 25 normal subjects (mean 0.90 with a SD of 0.13 ), while in 27 patients with mitral stenosis the ratio was considerably higher (mean $\mathrm{r} \cdot 93$ with a SD of 0.48 ). It appears, therefore, that the ratio left atrium to aorta allowed separation of patients in whom left atrial enlargement was present from those in whom it was considered to be absent (Fig. 4). Absolute left atrial size in the same patients yielded values that fell in the normal range in 20 per cent of patients with long-standing and chronic atrial fibrillation (18-40 mm; Hirata et al., 1969).
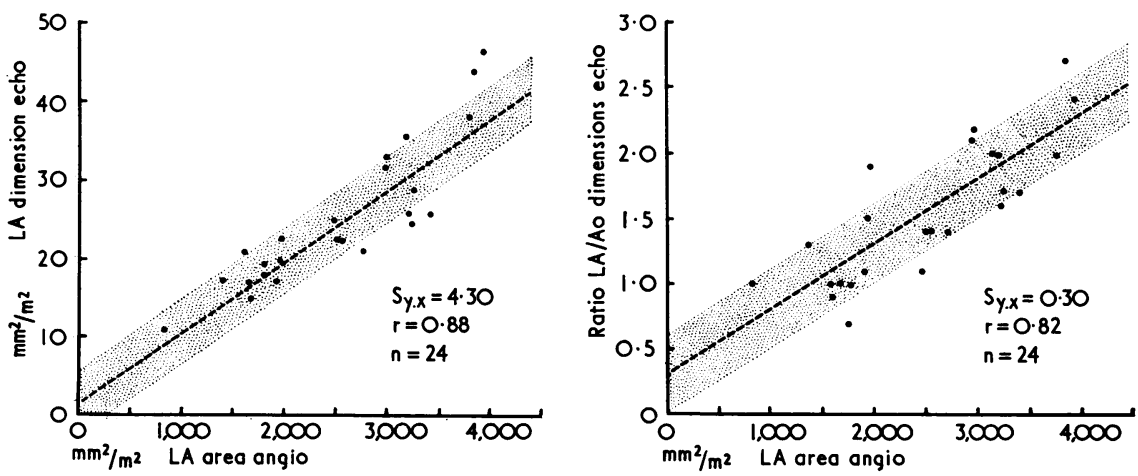

FIG. 3 The left panel shows the correlation between the echocardiographic left atrial dimension and left atrial area as determined by cineangiography. Both values for left atrial size are corrected for body surface area. Right panel: Correlation between the ratio of left atrial and aortic root dimensions by echocardiography and the left atrial area as determined by angiocardiography. The broken lines represent the calculated regression lines and the stippled area the standard error of the estimate $(S y \cdot x)$. 


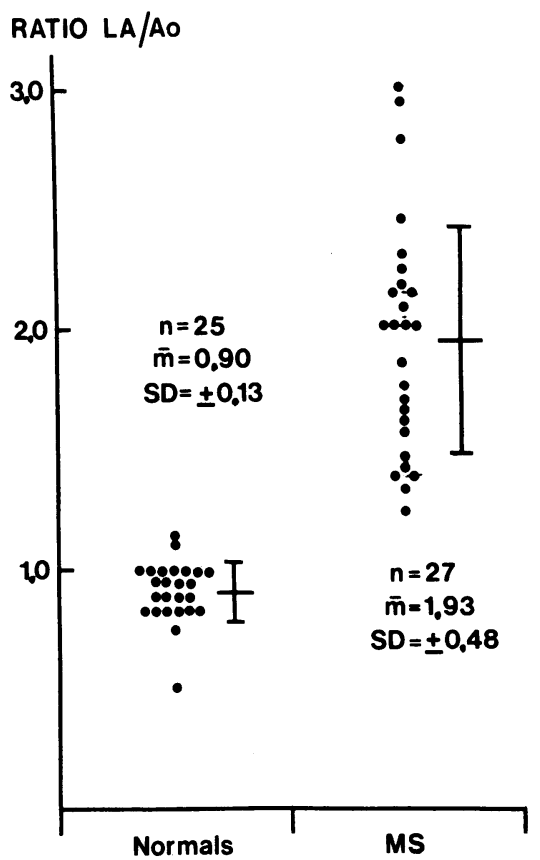

FIG. 4 The $L A /$ Ao dimensional ratios are shown for 25 normal subjects and 27 patients with mitral stenosis. Note that all normals centre around $I$ and that there is a clear separation from patients with mitral senosis.

\section{Left ventricular volume studies}

Tables 2 summarizes the results in the 35 patients. The uncorrected mean values for the echographic determined DD and SD were 51.6 and $40.8 \mathrm{~mm}$. Standard deviations from the mean were 10.04 and

LV end-diastolic volume

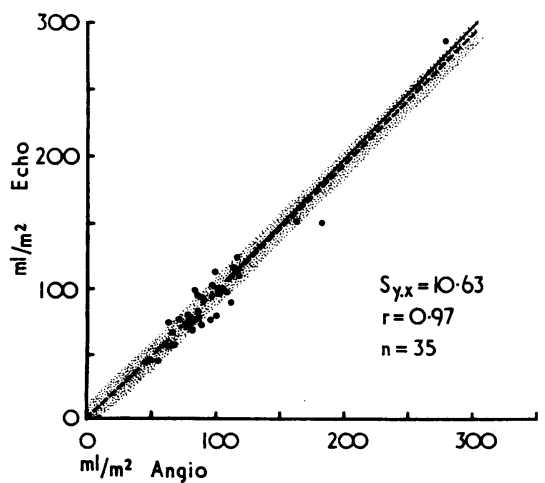

$7 \cdot 29 \mathrm{~mm}$, respectively. Mean values for echocardiographic and angiographic calculated end-diastolic volumes were 92.6 and $97.0 \mathrm{ml} / \mathrm{m}^{2}$. Standard deviation is 42.3 and $4 \mathrm{I} \cdot 9 \mathrm{ml} / \mathrm{m}^{2}$. The correlation coefficient is 0.97 and the calculated regression equation: echocardiogram (EDV) $=0.98$ angiogram (EDV) - 2.22. The standard error of the estimate (Sy.x) is $10.63 \mathrm{ml} / \mathrm{m}^{2}$.

Mean end-systolic volumes by echocardiogram and angiogram are 44.3 and $45.6 \mathrm{ml} / \mathrm{m}^{2}$ (standard deviation \pm 29.0 and $35.5 \mathrm{ml} / \mathrm{m}^{2}$ ). The correlation coefficient is 0.96 . The regression equation is echogram $(E S V)=0.83$ angiogram (ESV) +6.30 with Sy. $x=8.30 \mathrm{ml} / \mathrm{m}^{2}$. Fig. $5 \mathrm{a}$ and $\mathrm{b}$ show the relations between the angiographic and echocardiographic end-diastolic and end-systolic volumes, respectively. Mean stroke volume by echocardiography and angiography is 48.5 and $5 \mathrm{r} .4 \mathrm{ml} / \mathrm{m}^{2}$ (standard deviation \pm 19.5 and $13.2 \mathrm{ml} / \mathrm{m}^{2}$ ). Both methods correlate with $r=0.82$ and $r=0.79$, respectively. The regression equation is: echogram $(\mathrm{SV})=\mathrm{I} \cdot 2 \mathrm{I}$ angiogram $(\mathrm{SV})-$ 14.02 and Sy. $x=11 \cdot 07 \mathrm{ml} / \mathrm{m}^{2}$.

Mean ejection fraction is 54.3 and 44.9 per cent by echocardiography and angiography, respectively, with standard deviation \pm 13.08 and 11.7 per cent. The regression equation is echocardiography $(\mathrm{EF})=$ 0.88 , angiography (EF) +4.94 with Sy. $x=7.9$ per cent. Fig. $6 a$ and $b$ show diagrammatically the relations between both by angiogram and echocardiogram calculated stroke volume and ejection fraction.

\section{Discussion}

Only one previous study deals with the feasibility of assessing the left atrial size from a single anteroposterior echocardiogram dimension (Hirata et al.,

LV end-systolic volume

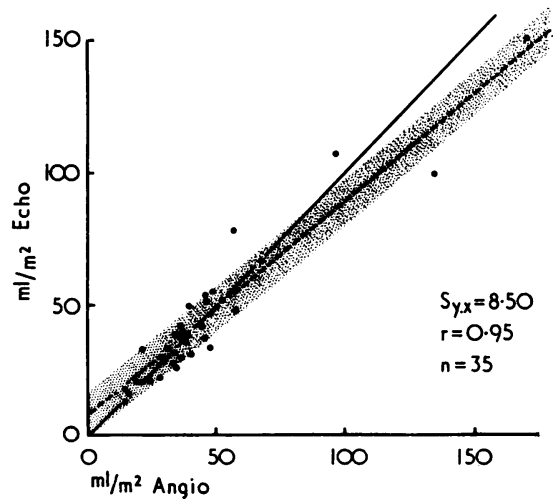

FIG. 5 The left panel shows the correlation between end-diastolic volumes calculated from echocardiography (ordinate) and angiography (abscissa). The right panel shows a plot of the end-systolic echographic volumes against the angiographic end-systolic volumes. Solid line is line of identity, broken line the regression line, and the stippled area represents the standard error of the estimate (Sy.x). 

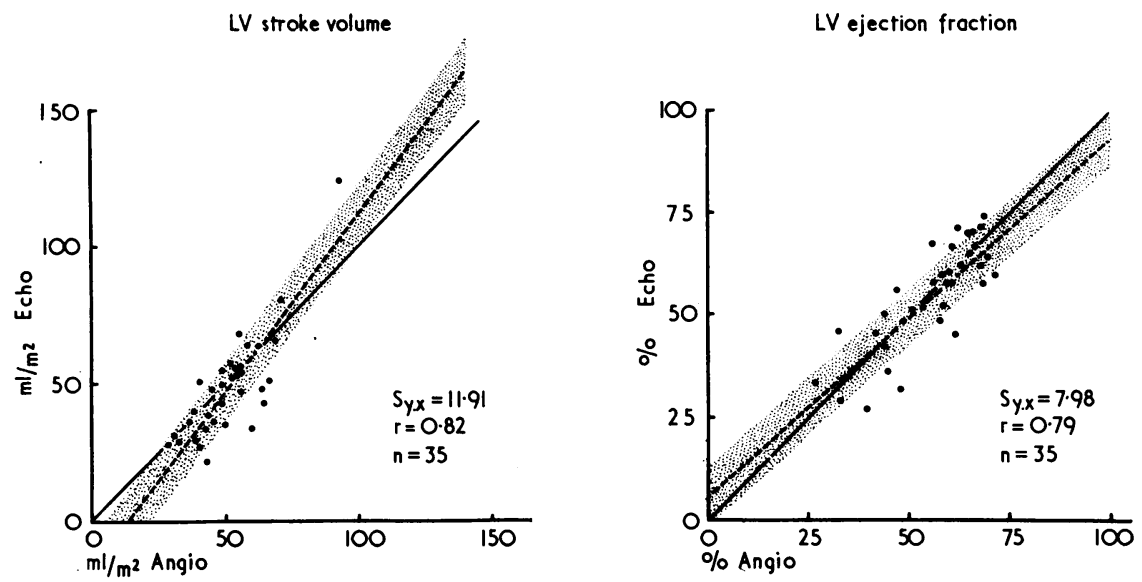

FIG. 6 Comparison of total left ventricular stroke volumes (left panel) and ejection fractions (right panel) by echocardiogram and angiogram. The line of identity is the solid line, the regression line the broken line and the stippled area the standard error of the estimate.

1969). These investigators found a good correlation with the left atrial area measured from selective left atrial cineangiograms in the right anterior oblique position $(r=0.91)$. Shortly after this study the walls of the left atrial chamber were also identified echocardiographically by means of Cardiogreen dye injections (Gramiak, Shah, and Kramer, 1969; Feigenbaum et al., 1970) which, by the added contrast (echoes from the blood containing the dye), permitted the validation of the accuracy of the echographic mesurements. The left atrial size has also been assessed from the suprasternal transducer position (Goldberg, 197I). The dimensions obtained in that study are about 30 per cent larger but the number of cases reported was not very large. The present study confirms the validity of estimating the left atrial size from a single anteroposterior standard dimension since the correlation coefficient $(r=0.88)$ was high and standard deviation small. The assumption made in the present study and in that by Hirata et al. (1969) was that the cineangiographic left atrial area in the right anterior oblique position is representative of the left atrial chamber size or volume. This is a questionable assumption for a normal left atrium but may well apply to enlarged left atria where the angiographic evidence shows that the shape becomes more globular. The problem in the use of left atrial dimensions is that there is a large variation in the normal left atrial dimension while correction for body surface area will restrict the range of normal values (Hirata et al., 1969). The late atrium/aorta ratio was found to be a useful empirical index in the individual patient at the bedside and gave better separation between the normal left atrium and left atrial enlargement than the absolute left atrial size. It is known from surgical experience that the sinuses of Valsalva, where echocardiographic dimensions are measured, rarely dilate in chronic aortic valve disease (poststenotic dilatation is always above the sinuses of Valsalva so that aortic dilatation should not invalidate this ratio). The application of echocardiography and its clinical usefulness in the estimation of left ventricular volumes has been shown in many recent studies (Popp et al., 1969; Popp and Harrison, 1970; Pombo et al., I971a, b; Fortuin et al., 197I; Feigenbaum et al., 1972; Murray et al., 1972; Belenkie et al., 1973; Gibson, 1973; Ratshin et al., 1973). Correlation coefficients in these studies for end-diastolic volumes ranged from $r=0.84$ to 0.97 . Values ranging from $\mathbf{r}=0.85$ to 0.97 have been found for end-systolic volumes. In addition to the estimation of left ventricular volumes, its pump function has been assessed from derived parameters such as stroke volume and ejection fraction (Pombo et al., I971a; Fortuin et al., 1971; Fortuin, Hood, and Craige, I972; Feigenbaum et al., 1972). Correlation coefficients for ejection fraction in the different reports are consistently less than for enddiastolic and end-systolic volumes and varied from $r=0.69$ to 0.81 .

The major problem in the calculation of left ventricular volumes by the conventional ultrasound method is that only one single dimension is employed to calculate the volume of the three-dimensional left ventricular chamber. With the assumption that the left ventricular chamber approximates the shape of an ellipsoid of revolution, the measured 
echogram dimension is assumed to represent the anatomical (or angiographic) minor left ventricular axis. It also implies that the measured dimension has a constant relation to the axis of the left ventricle at both end-systole and end-diastole and that this minor axis is indeed half as long as the long axis. It has been shown in experimental studies that major information about left ventricular volume and its change can indeed be obtained from its minor axis alone (Rushmer, Crystal and Wagner, 1953; Hawthorne, I96I; Lynch and Bove, 1969).

Two questions arise in the clinical situation where hearts may assume different shapes: I) should the same formula which is applied to a small (normal) heart be used for an enlarged (diseased) heart, and 2) what errors are introduced by localized disorders in wall motion? I) It is known that the minor axis becomes relatively larger as compared to the long axis in dilated ventricles (Fortuin et al., 1971; Teichholz et al., 1972; Popp and Harrison, 1973). Though there are only a few patients with larger left ventricular volumes included in this series from which to draw any conclusions, it was found that no systematic overestimation of the larger volumes occurred, though this could have been expected particularly when the left ventricular shape was more spherical. In addition other recent studies demonstrate that echocardiography allows reliable quantitation of end-diastolic and endsystolic volumes over a wide range of left ventricular sizes (Ratshin et al., I973) by applying the volume formula of a prolate ellipse. 2) Since coronary artery disease presently represents the largest group of patients in cardiological practice, the second question is more important. While the majority of these patients do not have pronounced dilatation of their left ventricle, most of them do have abnormally contracting segments. Thus, the use of the echographic minor axis should be reasonably accurate in the calculation of end-diastolic volume but the estimation of end-systolic volume might not be satisfactory. It was indeed found that angiographic and echocardiographic end-systolic volumes did not correlate as well as did end-diastolic volumes. Furthermore the accuracy of the echographic estimated end-systolic volumes appeared to be related to the location of the dyskinetic or akinetic segment and not to its extent (Ratshin et al., 1973). These observations seem to invalidate the derived stroke volumes and ejection fractions, particularly in this group of patients where the non-invasive continuous assessment of the left ventricular function is most desired. However, good semi-quantitative estimates of left ventricular volumes and function can be obtained from echographic measurements. Its non-invasive nature and the potential of serial de- terminations (Redwood, Henry, and Epstein, 1973), even in the critically ill, stimulate continuing research in this field.

We are grateful to Mrs. I. Tiggelaar - de Widt and Mrs. S. Leenheer for their technical assistance.

\section{References}

Belenkie, I., Nutter, D. O., Clark, D. W., McCraw, D. B., and Raizner, A. E. (1973). Assessment of left ventricular dimensions and function by echocardiography. American Fournal of Cardiology, 31, 755.

Bom, N., Lancée, C. T., van Zwieten, G., Kloster, F. E., and Roelandt, J. (1973). Multiscan echocardiography I. Technical description. Circulation, 48, 1066.

Feigenbaum, H., and Chang, S. (1972). Echocardiography. Lea and Febiger, Philadelphia.

Feigenbaum, H., Popp, R. L., Wolfe, S. B., Troy, B. L., Pombo, J. F., Haine, C. L., and Dodge, H. T. (1972). Ultrasound measurements of the left ventricle. A correlative study with angiocardiography. Archives of Internal Medicine, 129, 461.

Feigenbaum, H., Stone, J. M., Lee, D. A., Nasser, W. K., and Chang, S. (1970). Identification of ultrasound echoes from the left ventricle by use of intracardiac injections of indocyanine green. Circulation, 41, 615.

Feigenbaum, H., Zaky, A., and Nasser, W. K. (1967). Use of ultrasound to measure left ventricular stroke volume. Circulation, 35, 1092.

Fisher, R. A. (1970). Statistical Methods for Research Workers, I $4^{\text {th }}$ ed. Oliver and Boyd, Edinburgh.

Fortuin, N. J., Hood, W. P., Jr., and Craige, E. (1972). Evaluation of left ventricular function by echocardiography. Circulation, 46, 26.

Fortuin, N. J., Hood, W. P., Jr., Sherman, M. E., and Craige, E. (197I). Determination of left ventricular volumes by ultrasound. Circulation, 44, 575.

Gibson, D. G. (1973). Estimation of left ventricular size by echocardiography. British Heart fournal, 35, 128.

Goldberg, B. B. (1971). Suprasternal ultrasonography. fournal of the American Medical Association, 215, 245.

Gramiak, R., Shah, P. M., and Kramer, D. H. (I969). Ultrasound cardiography: contrast studies in anatomy and function. Radiology, 92, 939.

Greene, D. G., Carlisle, R., Grant, C., and Bunnell, I. L. (1967). Estimation of left ventricular volume by oneplane cineangiography. Circulation, 35, 6r.

Hawthorne, E. W. (I96I). Instantaneous dimensional changes of the left ventricle in dogs. Circulation Research, 9, I10.

Henry, W. L., Clark, C. E., and Epstein, S. E. (1973). Asymmetric septal hypertrophy. Echocardiographic identification of the pathognomonic anatomic abnormality of IHSS. Circulation, 47, 225.

Hirata, T., Wolfe, S. B., Popp, R. L., Helman, C. H., and Feigenbaum, H. (1969). Estimation of left atrial size using ultrasound. American Heart fournal, 78, 43.

Lynch, P. R., and Bove, A. A. (1969). Geometry of the left ventricle as studied by a high-speed cineradiographic technique. Federation Proceedings, 28, 1330.

Murray, J. A., Johnston, W., and Reid, J. M. (1972). Echocardiographic determination of left ventricular dimensions, volumes and performance. American fournal of Cardiology, 30, 252.

Pombo, J. F., Russell, R. O., Jr., Rackley, C. E., and Foster, G. L. (197Ib). Comparison of stroke volume and cardiac output determination by ultrasound and dye dilution in acute myocardial infarction. American fournal of Cardiology, 27,630 . 
Pombo, J. F., Troy, B. L., and Russell, R. O., Jr. (I971a). Left ventricular volumes and ejection fraction by echocardiography. Circulation, 43, 480.

Popp, R. L., and Harrison, D. C. (1970). Ultrasonic cardiac echocardiography for determining stroke volume and valvular regurgitation. Circulation, 4I, 493.

Popp, R. L., and Harrison, D. C. (1973). The use of ultrasound in cardiac diagnosis. In Non-invasive Technics in Cardiac Evaluation, p. 149. Ed. by A. M. Weissler. Grune and Stratton, New York.

Popp, R. L., Wolfe, S. B., Hirata, T., and Feigenbaum, H. (1969). Estimation of right and left ventricular size by ultrasound. American fournal of Cardiology, 24, 523.

Ratshin, R. A., Boyd, C. N. Jr., Rackley, C. E., Moraski, R. E., and Russell, R. O. (1973). Quantitative echocardiography: correlations with ventricular volumes by angiocardiography in patients with coronary artery disease with and without wall motion abnormalities. Circulation, 48, Suppl. IV, 48.
Redwood, D. R., Henry, W. L., and Epstein, S. E. (1973). Evaluation of the ability of echocardiography to measure alterations in left ventricular volume. Circulation, 48, Suppl. IV, 206.

Roelandt, J., Kloster, F., ten Cate, F. J., Bom, N., Lancée, C. T., and Hugenholtz, P. G. (1973). Multiscan echo cardiography: description of the system and initial results in 100 patients. Heart Bulletin, 4,51 .

Rushmer, R. F., Crystal, D. K., and Wagner, C. (1953). Functional anatomy of ventricular contraction. Circulation Research, 1, 162.

Teichholz, L. E., Kreulen, T. H., Herman, M. V., and Gorlin, R. (1972). Problems in echocardiographic volume determinations: echo-angiographic correlations. Circulation, 46 (Suppl. II), II, 5 I.

Requests for reprints to Professor J. Roelandt, Department of Clinical Echocardiography, Thoraxcenter, P.O. Box 1738, Rotterdam, The Netherlands. 